\title{
Automation of mazes and shuttleboxes
}

\author{
G. A. HEIGHINGTON and G. B. BIEDERMAN \\ University of Toronto, West Hill, Ontario MIC IA4, Canada
}

\begin{abstract}
Automation of the movement of doors in mazes and shuttleboxes may be readily achieved by a simple modification to apparatus commonly found in laboratory settings. Using a commercial timer module fitted with a "take-up" spool, a simple pulley may be arranged to lift and lower doors to permit and/or restrict access to certain areas of mazes and shuttleboxes, obviating experimenter handling.
\end{abstract}

It is commonly accepted in psychology laboratories that nonautomated animal mazes or shuttlebox devices are subject to subtle experimenter biases which may invalidate some classes of maze research. Experimenter handling of animals (e.g., to replace the subject in the start compartment) is clearly undesirable during intertrial intervals in certain experiments. Manually opening and closing access points in mazes may be subject to similar experimenter-originated problems because of biased timing factors.

Automation of the movement of doors in mazes may, of course, be accomplished through a wide variety of

The research employing the apparatus described was supported in part by a grant from the National Research Council of Canada to the second author. Reprint requests should be mailed to the first author at the Division of Life Science, Scarborough College, University of Toronto, West Hill, Ontario M1C 1A4, Canada. apparatus arrangements. Anything from a solenoid to a linear actuator may be used to automatically stop the movement of swinging doors hinged at the top or side, and motors of all varieties may be used via pulley systems to raise and lower doors. The latter arrangement seems to have some advantages in minimizing the animal's difficulty in entering or leaving some portion of the maze.

We describe here one convenient and inexpensive automated arrangement for opening and closing lightweight doors by a vertical movement.

\section{THE APPARATUS}

A timer module (in this case, a Grason-Stadler E4430 timer, $0-15 \mathrm{sec}$ ) was used which had the advantage of containing operate and report circuits. The manufacturersupplied dial was removed and an aluminum spool ( $3 \mathrm{~cm}$ in diam, $1.5 \mathrm{~cm}$ in track width) was fitted to the

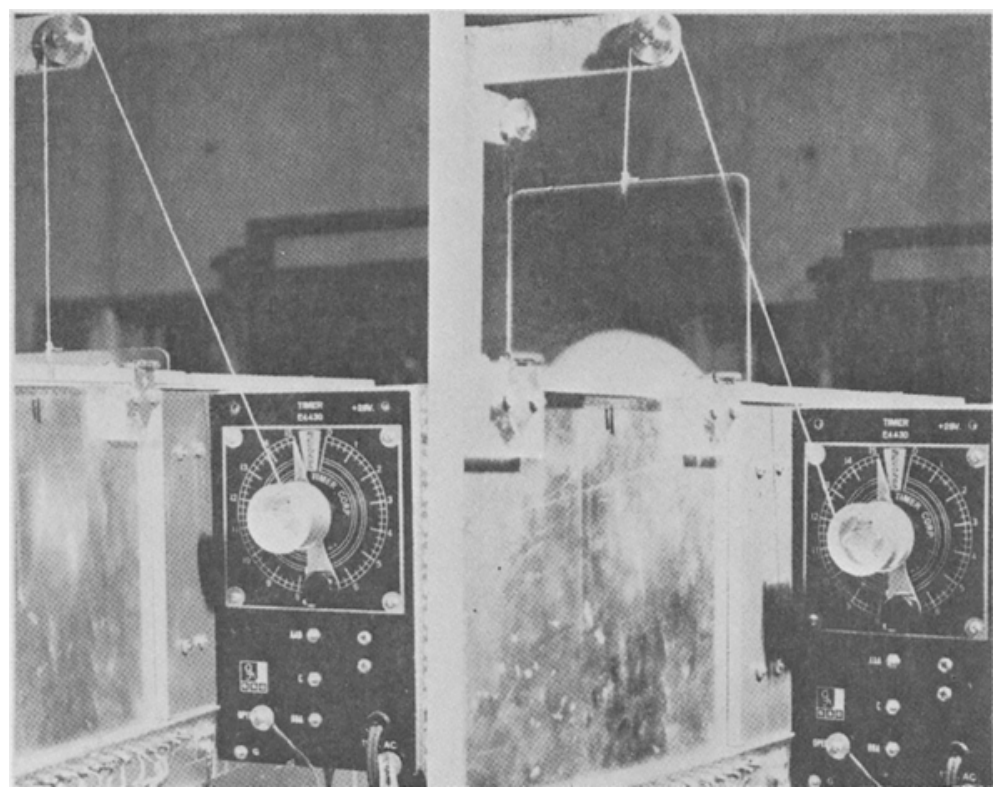

Figure 1. Right panel: maze door lifted by timer spool. Left panel: maze door closed. 
timer shaft by a machine screw. The spool wound a wire attached via a pulley (see Figure 1) which, in turn, raised and lowered the door in the maze. This module has a clutch mechanism that immediately stops the door's movement when the end of the timing period is reached.

In the present application, the door is raised completely during the operation of the timer (in $15 \mathrm{sec}$ ). The door remains at this position until the operate circuit is opened. Lowering of the door occurs during the reset of the timer (in about $1 \mathrm{sec}$ ). Sensing devices (photocells, switches sensitive to weight, etc.) can be arranged to prevent the door dropping on the animal. The timer module has been fitted to the side of the maze (see Figure 1) and connects to the door, which rises on a simple track arrangement (not shown) via a flexible wire through a single pulley.

The use of the timer module to raise and lower the Plexiglas door $(100 \mathrm{~g}, 18 \times 13 \mathrm{~cm}$ in the present case) has the advantage of coming equipped with the clutch and logic mechanism, which simplifies the automation procedure and obviates the need to arrange motors and gear systems to accomplish a similar end. Suitable timers may, of course, be selected (e.g., $0-3 \mathrm{sec}, 0-60 \mathrm{sec}$ ) that will conveniently raise doors of different sizes at varying speeds.

Excluding the cost of the timer module (which would undoubtedly appear in the logic circuit of the maze apparatus in any event), the cost of materials (spool, pulley, fittings, etc.) is under $\$ 5$.

Devices similar to the one described here have been in operation in a two-door $Y$-maze in this laboratory for several months and for thousands of trials without incident.
(Received for publication May 10, 1977; accepted June 10, 1977.) 